\title{
Reply to Lebech or the ontological humilit of the lawyer faced with philosophical consistency
}

\author{
Judge Christian Byk University of Poitiers, France
}

\begin{abstract}
Replying to the criticisms of Lebech, the author tries, regarding the issue of embryo research, to draw a line between what could be an international legal approach and what is a philosophical ontological quest. It is then up to the reader to decide if, and how far, these two different approaches can be complementary.

(Fournal of Medical Ethics 1998;24:348-349)
\end{abstract}

Keywords: European Convention on Biomedicine; embryo research; legal status

The comments made by Lebech on "my" proposed draft protocol for the European Convention on Biomedicine relating to research on the human embryo and fetus give me a good opportunity to reassert the main elements of my proposal.

Although this proposal was made in the context of my work as legal adviser to the Secretary General of the Council of Europe, my objective in drafting such a protocol was more to give an example of the kind of text, from the point of view of wording and drafting, that might work as a basis for European discussion (and suggest, in some areas, possible compromises) than to contribute, even very modestly, to the present work of the Steering Committee on Bioethics of the Council of Europe (CDBI) on such matters. Very few people indeed - including physicians, philosophers and also lawyers - understand what is required by an international approach to the discussion of sensitive bioethical issues and how such an approach might be reflected in the texts that circulate within both national governments and international institutions.

However, I must recognize that Lebech has grasped my pedagogical approach, as is made clear when she says that "the proposed protocol ... pretends to clarify not what the human embryo is but what it could be regarded as - given the political circumstances".

Undoubtedly she is irritated by this approagh. Certainly her main criticism is that, so far as the public debate which we both call for, is concerned, "what we were awaiting was not a protocol relating to research on the human embryo ahd fetus" but "on the legal status of the hum embryo".

I have no better answer to make her than $\vec{\Phi}_{\infty}$ remind her that this choice is a political one sensitive at the national level and therefore very problematical at the international one. Hower, we can note that the Committee of Ministersof the Council of Europe has been inspired bo a "well-orientated public debate" and has now mandated the CDBI to work on such a protogotil. In the meantime it seems possible to derive from the existing or proposed texts (including the above mentioned draft protocol) on embryo research an implicit status regarding the human embryo a fetus or elements for such a status. Lebech's further criticisms constitute no more than a re-statement of her view that in general ghe protection afforded to the embryo or fetus is pot sufficient.

Let me respond to some of her comments. Q of the major criticisms is "that the permissiven relating to embryos conceived in vitro will now erode the protection of embryos conceivednin utero". I could agree that it is probably not a gold policy to cover in the same protocol the two types of embryo research. However, I did this in my paper, on purpose, because my starting point for the examination of research on embryos in vitro was to try and derive some rules for such researh from the existing rules which apply to research vulnerable persons, which means, amongst othess, pregnant women and consequently embryos fetuses in utero.

And on this point the commentator should know that such research is authorised by many 
legislations and professional codes of practice. We may even note here, that the draft protocol of the Council of Europe on human research shows that the council is thinking of letting pregnant women freely exercise their autonomy, by no longer considering them as vulnerable persons to be overprotected. I would also point out that the conditions I have introduced in articles four and five are generally stricter than those currently applying in many places.

Finally, I do not understand how the obligation to destroy an embryo which has been used for research (as is stated in the Danish legislation) can apply to an embryo in utero. If the research occurs prior to implantation, the embryo will then not be implanted but if an embryo in vitro has not been subject to research and then is implanted and submitted through the pregnant woman to research, pregnancy should not be ended for this sole reason.

As regards the use of the term "therapeutic research" applying to research with a therapeutic objective for both the subject of the research and others, it could certainly be replaced by the expression "research with no direct benefit". Lebech is also right when she notes that article seven leaves the conditional prohibitions on cryopreservation and germ-line cell therapy up to the national authorities. It is simply my feeling that it would be difficult at the present time to reach further consensus, as is shown by the Universal Declaration on the Human Genome adopted by Unesco on 11 th November 1997. I also choose to leave this door open because I believe there could be some interest, some benefit, in regulated cryopreservation and germ-line cell therapy.

Article nine is not legalising all research on "spare" embryos but is giving two limited legitimate endpoints for such research. It will then be the mandate of authorities, such as the Human Fertilisation and Embryology Authority in the UK, to make explicit the meaning of these objectives regarding the research submitted for permission. ${ }^{1}$

Finally, regarding Lebech's conclusion, I agree with its main point: "it is impossible to accept the proposal for a protocol as it stands".

A proposal is indeed a basis for discussion not for approval. It provides, if not a provocative approach to induce discussion, at least a clear idea of what the author intends to demonstrate. My idea was to use the comparison between research on vulnerable persons, which is nowadays allowed in most countries, and research on embryos, to derive a guideline for the protection of the embryos submitted to research.

I agree (and apologize) that I could have been misunderstood; and that I could have done useless work because what I proposed was not what some "are still in want of", namely "the legal status of the human embryo" with the implicit idea that such status should prohibit all embryo research, giving then to the embryo a better protection than to (other) vulnerable persons.

Fudge Christian Byk is Associate Professor at the University of Poitiers, France and the Secretary General of the International Association of Law, Ethics and Science. He was the French representative to the now titled Steering Committee on Bioethics (19831991) and Special Advisor to the Secretary General of the Council of Europe (1991-1993).

\section{References}

1 Human Fertilisation and Embryology Authority. Sixth annual report. London: HFEA, 1997: 7, para 4 and annex 6. 